\author{
Bahadir Sarli, Eyup Ozkan, Melih \\ Demirbas and Ahmet $\mathrm{O}$ Baktir \\ Kayseri Education and Research Hospital, \\ Department of Cardiology, Kayseri, Turkey \\ Dates: Received: 25 August, 2015; Accepted: 10 \\ October, 2015; Published: 12 October, 2015 \\ *Corresponding author: Assoc. Prof. Bahadir Sarli, \\ MD, Kayseri Education and Research Hospital, \\ Department of Cardiology, 3810, Kayseri, Turkey, Tel: \\ +90 535 3040445; Fax: +90 352 3207313; E-mail: \\ drsarli@yahoo.com \\ www.peertechz.com \\ ISSN: 2455-2976
}

\section{Case Report \\ Multiple Giant Coronary Arterial Aneurysms Leading to Stable Angina}

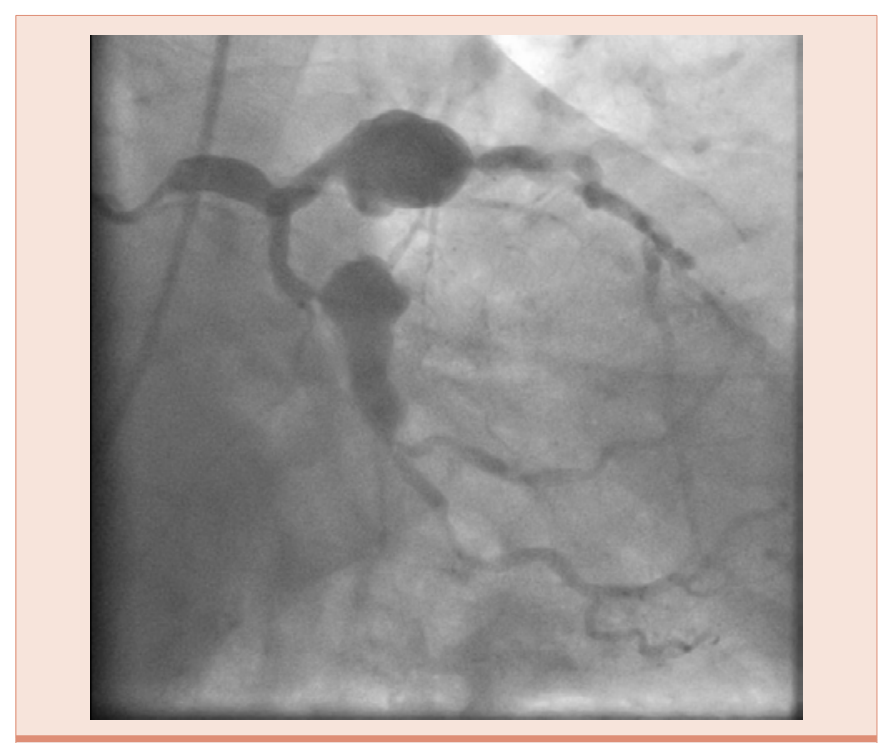

Figure 1: Coronary angiography image showing giant aneurysms on left anterior descending artery $(20 \times 18 \mathrm{~mm})$ and left circumflex artery $(16 \times 20 \mathrm{~mm})$ and atherosclerotic stenosis proximal and distal to the aneurysms.

stasis in the dilated segments and impaired coronary flow. Treatment options vary from aggressive surgical ligation of the aneurysm, in union with distal bypass surgery, to percutaneous implantation of a covered stent or conservative medical management with continued antiplatelet therapy. Surgical correction is generally accepted as the preferred treatment for giant coronary artery aneurysms [5].

\section{References}

1. Crawley PD, Mahlow WJ, Huntsinger DR, Afiniwala S, Wortham DC (2014) Giant coronary artery aneurysms: review and update. Tex Heart Inst J 41: 603-608.

2. Sarli B, Baktir AO, Saglam H, Arinc H, Kurtul S, et al. (2014) Neutrophilto-lymphocyte ratio is associated with severity of coronary artery ectasia. Angiology 65: 147-151.

3. Mouine N, Bennani R, Amri R (2014) A giant left ventricular pseudoaneurysm in Behçet's disease: a case report. Cardiol Young 24: 382-383.

4. Suzuki H, Daida H, Tanaka M, Sato H, Kawai S, et al. (1999) Giant aneurysm of the left main coronary artery in Takayasu aortitis. Heart 81: 214-217.

5. Bajaj S, Parikh R, Hamdan A, Bikkina M (2010) Covered-stent treatment of coronary aneurysm after drug-eluting stent placement: case report and literature review. Tex Heart Inst J 37: 449-454.

Copyright: (c) 2015 Sarli B, et al. This is an open-access article distributed under the terms of the Creative Commons Attribution License, which permits unrestricted use, distribution, and reproduction in any medium, provided the original author and source are credited. 